\section{The animal rights question}

SIR - It was good to read Barbara Culliton's clear and critical appraisal of the problems faced by the medical research community as a result of increasingly hostile campaigns by animal rights groups (Nature 351, 517; 1991). Although there has been organized protest against animal research for over 100 years, during the past two decades we have had to deal with the far more aggressive animal rights movement. Since the mid-1970s, there have been enormous improvements in the welfare of laboratory animals and controls on their use, but the same period has seen protests against their use escalate from fringe status to a movement embracing both outright terrorism and multimillion pound campaigning organizations.

Nobody would deny that we have a responsibility to preserve the well-being of animals in our charge; the welfare of laboratory animals is a primary concern for the researchers and technicians who work with them. This stands in clear contrast to the idea of 'animal rights', which argues that other sentient animals have similar rights to humans, making it morally wrong for humans to use them in any way: in agriculture, zoos, sport, research or even as pets.

Without animal studies, fundamental physiology, probably the earliest experimental medical science, could not have made significant progress. Immunology and pharmacology could not have become established without experiments on mice, rats and rabbits. Animal studies continue to play a crucial part in genetics, toxicology, pathology, endocrinology, neurobiology and developmental biology and surgery. The huge advance in our ability to diagnose and treat disease over the past 50 years has, to a great extent, depended on animal research.

Yet despite this, new legal controls on how and why animals can be used in research were introduced in Britain five years ago, and despite the fact that they are regarded internationally as the most comprehensive and exacting anywhere, the animal rights movement continues to push for tougher legislation. The truth is that, in Britain, the controls are so tight that administrative delays are already threatening to hold back progress in some areas of research.

For many years, the general principle of "keep your head down and it will go away" dominated the thinking on how to deal with this problem. But now there is a growing conviction in the scientific and medical community that the problem has become too serious to ignore. The general public is being actively misled by the animal rights movements into believing that animal research is both cruel and pointless. Unless the medical and scientific community makes greater efforts to explain to the press, the public and politicians why animals are used in research and the benefits which have come from that use, we can look forward only to greater pub- lic antagonism, more hostile reporting and, eventually, more restrictive legislation.

Culliton is concerned chiefly with the animal rights problem in the United States, but the same sort of campaigning has been going on for much longer in Britain, has been more intense and far more violent. There is hardly a university or pharmaceutical company in Britain that has not suffered from the attentions of the animal rights movement. There is every indication that the level of protest will continue to rise, until sufficient effort is devoted to telling the public the truth. The growing danger to animal research comes not only from the activity of the animal rights movement, but also from the inactivity of those who should be defending it. Mark Matfield

Research Defence Society,

Grosvenor Gardens,

London SW1W OBS, UK

SIR - Barbara Culliton wonders at the growing support for animal rightists in the United States. Part of the reason is that thoughtful members of the public troubled by - say the use of chimpanzees in AIDS research can always hope that some sensible synthesis can be made of the animal rightist nonsense and medical establishment nonsense (of which the article in question is an excellent example). You do not need to be a philosopher or a theologian to know that there is something very dodgy about sacrificing chimpanzees for purely human purposes, and to know that this version of Cain's question ("Am I my brothers keeper?") - and others like it - requires a great deal of serious thought and public debate.

This is a vexed and troubling question to which I for one certainly do not know the answer. What I do know is that the debate that might help us find it is unlikely to be inaugurated by statements like "The animal rights people go for the heart, the biologists for the head". This is not a contribution to any debate, but an attempt to disqualify one of the possible parties to it.

If my teaching experience in undergraduate ethics is anything to go by, many people are ready for a much more serious discussion of these questions than the 'research community' is willing to offer. If it really intends to maintain this tone, it will lose the debate by default, and will deserve to. Someone has to make us think about these questions, and if it isn't the research community or the churches or the universities it will be the animal rightists: unattractive, bigoted and disingenuous though they may be. Cromwell would have approved "...since the work must go on, better plain men than none".

Department of Pure Mathematics and Mathematical Statistics, University of Cambridge, Cambridge CB1 2SB, UK.
Astronomers still
thinking too big?

SrR - One must give the advocates of "big science" credit for persistence in the face of adversity. One might have thought that the Hubble Space Telescope debacle would have taught US astronomers the folly of "putting all of your eggs in one basket", particularly if you plan to put that "basket" into high Earth orbit, where correcting errors will be both difficult and costly. Instead, at the top of the Bahcall committee's "wish list" for US astronomy, we find the Space Infrared Telescope Facility (SIRTF).

It takes only a simple exercise in arithmetic to see how lopsided the Bahcall committee's recommendations really are. Of $\$ 1,550 \mathrm{mil}-$ lion recommended for "large projects", SIRTF would get $\$ 1,300$ million. That $\$ 1,300$ million is larger than the total of $\$ 1,222$ million allocated to all moderate programmes and more than five times the $\$ 251$ million left for small programmes. Although the priorities of the Bahcall committee are presented as those of a limited astronomy community, I suspect that many of the astronomers supported by "small programmes" might have dissented, had their opinion been asked.

RoBert J. Yaes

University of Kentucky, Medical Center, Department of Radiation Medicine,

Lexington,

Kentucky 405036-0084, USA

\section{Digital display}

SIR - In your article "Secret Service as ultimate referee" (Nature 350 553; 1991), you discuss the possibility that a person might transcribe data with a preference for certain digits. This was well documented nearly 40 years ago by $\mathrm{H}$. Gysel (Mikrochimica Acta $267 ; 1953)$, in the case of analysts weighing samples for carbon and hydrogen elemental analyses where the last place of decimals of the weight had to be estimated. He found that there was an unconscious preference for certain digits that was fairly constant for each chemist, and the errors thus induced could influence the results by up to 0.25 per cent in the analysis. At the time, many journals required accuracy to within 0.3 per cent. Gysel discussed the allowance that should be made for this preference, and later (Mikrochimica Acta 577; 1956) he shows how replacing the balances with those using a different system helped.

This not only supports your argument, but it even suggests that if there is not a preference, your random number idea has in fact been used.

Research Department,

Alan F. Thomas

Firmenich $S A$,

Case Postale 239,

$\mathrm{CH}-1211$ Geneva 8,

Switzerland 